\title{
DEVELOPMENT OF AN INTELLIGENT DECISION MODEL FOR NON-TRADITIONAL MACHINING PROCESSES
}

\author{
Shankar Chakraborty ${ }^{1^{*}}$ and Vidyapati Kumar ${ }^{1}$
}

1Department of Production Engineering, Jadavpur University, Kolkata, India, 700032

Received: 10 January 2021;

Accepted: 7 March 2021;

Available online: 13 March 2021.

\begin{abstract}
Original scientific paper Abstract. In order to fulfil the ever increasing requirements of various hard and difficult-to-machine materials in automobile, turbine, nuclear, aviation, tool and die making industries, the conventional material removal processes are now being continuously substituted by an array of non-traditional machining (NTM) processes. The efficient and improved capabilities of these NTM processes have made them indispensible for the present day manufacturing industries. While deploying a particular NTM process for a specific machining application, the concerned process engineer must be aware of its capability which is influenced by a large number of controllable parameters. In this paper, an intelligent decision model is designed and developed in VBASIC to guide the concerned process engineer to have an idea about the values of various NTM process responses for a given parametric combination. It would also advise about the tentative settings of different NTM process parameters for achieving a set of target response values. It would thus aim in assisting the process engineers and designers to efficiently identify the technically feasible NTM processes in the early design and machining stages, focusing more on developing the required product functionalities and appearance with the feasible processes in mind, utilizing the process characteristics more effectively. The operational procedure of this developed decision model is demonstrated with the help of three real time examples.
\end{abstract}

Key words: Non-traditional machining process; Parameter; Response; Decision model; VBASIC.

\section{Introduction}

The emerging need for generating intricate and precise shape features in various advanced engineering materials, like high-strength-temperature-resistant alloys, tungsten carbide, titanium and its alloys, ceramics, fibre-reinforced composites,

* Corresponding author.

E-mail addresses: s_chakraborty00@yahoo.co.in (S. Chakraborty), crewvidyapati@gmail.com (V. Kumar). 
stainless steel, refractories etc. has resulted in development of a group of new machining processes, collectively known as non-traditional machining (NTM) processes. These advanced materials, having higher strength, toughness, hardness, low machinability and other varied properties, are in demand in various manufacturing industries, like automobile, nuclear, aviation, missile, tool and die making etc. In conventional machining processes, material removal usually takes place in the form of chips while applying forces on the workpiece using a wedge-shaped cutting tool which is harder than the work material. These processes usually incur higher cost with respect to tool wear and poor quality due to the generation of residual stresses in work material. They are also incapable to attain the dimensional accuracy and surface finish as desired by the modern day manufacturing industries. In these processes, as the relative motion between the tool and workpiece is typically rotary or reciprocating, the generated shape is thus restricted to only circular or flat features, and except in computer-numerical control (CNC) tools, machining of threedimensional surfaces is extremely difficult. Thus, in order to cater the needs of higher dimensional accuracy (in micro- or nano-level), surface finish, capability to machine difficult-to-cut materials with high strength-to-weight ratio, low surface damage, minimum tolerance, automated data transmission and miniaturization, the conventional machining processes are now being gradually replaced by the NTM processes (Jain, 1980; Pandey \& Shan, 1980; El-Hofy, 2005). In NTM processes, instead of sharp cutting tools, energy in its direct form is employed to remove material from the workpiece surface. These processes usually adopt mechanical, thermal, electrical and chemical energies or any combination of them for removing materials in the shape of micro-chips or atoms to achieve the desired accuracy and machined surface without any burr. In these processes, there is also no physical contact between the tool and workpiece, and the related material removal mechanism is not dependant on the mechanical properties of the work materials. Some of the NTM processes can also machine workpieces in areas inaccessible for the conventional machining techniques. Thus, these enhanced and efficient capabilities of NTM processes have made them almost indispensible and popular at the shop floor (Rajurkar et al., 2017). Over the years, more than 20 different NTM processes have been successfully developed and deployed to meet the diverse needs of the present day manufacturing industries. In order to make efficient use of the NTM processes, it thus becomes necessary to understand the exact nature of the machining problem. They can never replace the conventional machining processes, and a particular NTM process may be highly acceptable for a given set of requirements, but it may sometimes fail to prove its acceptability under different machining conditions. Thus, an extensive knowledge regarding the capabilities of various NTM processes is crucial in order to select the most suitable NTM process to generate the desired shape feature on a given work material. Existence of a large number of NTM processes with diverse uniqueness and capabilities has compelled the process engineers to develop structured approaches for NTM process selection for assorted machining applications. In this direction, development of a decision making framework in the form of an intelligent knowledgebased system is worth demanding. The developed intelligent decision model would help the process engineers in multi-directional ways, like (a) selecting the most suitable NTM process for a given problem, (b) managing a huge volume of machining data and responding quickly, (c) standardizing the conclusions drawn from a given data set, and (d) capturing the scarce expertise and making it available for subsequent use.

The remainder of the paper is organized as follows. Section 2 presents the applications of different methodologies adopted by the past researchers for NTM 
processes selection. Section 3 describes the developmental framework of the decision model. Section 4 presents three examples to demonstrate the applicability and usefulness of the developed model. Finally, Section 5 concludes the paper, highlighting its assumptions, limitations and future directions.

\section{Literature review}

Yurdakul \& Cçogun (2003) proposed an NTM process selection method for a given application requirement while combining analytic hierarchy process (AHP) and technique for order of preference by similarity to the ideal solution (TOPSIS). The alternative NTM processes were first narrowed down to a set of feasible solutions which were subsequently ranked based on their suitability for the desired application. Chakraborty \& Dey (2006) developed an AHP method-based expert system with a graphical user interface to find out the most apposite NTM process with the highest acceptability index value. Chakraborty \& Dey (2007) applied quality function deployment (QFD) methodology for identification of the most suitable NTM process for a given industrial application based on the development of a house of quality matrix for comparing the considered product and process characteristics. Chakladar \& Chakraborty (2008) integrated AHP and TOPSIS methods in order to select the most appropriate NTM process for a specific work material and shape feature combination. Chandraseelan et al. (2008) developed a web-based knowledge base system for identification of the most suitable NTM process based on some input parameters and process capability requirements. Chakladar et al. (2009) proposed a digraph-based approach to entirely automate the NTM process selection procedure. Based on the capabilities of the considered NTM processes to generate a desired shape on a given material, they were subsequently ranked in decreasing order of preference. Sugumaran et al. (2010) presented a neural network-based approach to help the process engineers in preparing a list of feasible NTM processes for a specific machining operation on a given work material. Karande \& Chakraborty (2012) solved four real time NTM process selection problems while applying an integrated PROMETHEE (preference ranking organization method for enrichment evaluation) and GAIA (geometrical analysis for interactive aid) approach. Temuçin et al. (2013) employed both fuzzy and crisp-based approaches to solve NTM process selection problems, and developed a decision support model to assist the process engineers to arrive at the correct NTM process selection decision. Roy et al. (2014) first applied fuzzy AHP method for estimating the relative importance of various NTM processes based on several product and process characteristics, and later adopted QFD methodology for evaluating the performance scores of various NTM processes to choose the best one. Sarkar et al. (2015) proposed a multi-objective optimization on the basis of ratio analysis (MOORA) method-based decision support system for selection of NTM processes having a given set of quantitative and qualitative selection attributes. Madić et al. (2015b) combined AHP, MOORA and TOPSIS methods for determination of the relative significance of various quality criteria, and hence, selection of the most suitable NTM process for a given application. Based on a hybrid multi-criteria decision making (MCDM) framework, Azaryoon et al. (2015) developed a knowledge-based system for identification of NTM processes. The developed approach employed the combined applications of decision making trial and evaluation laboratory (DEMATEL), analytic network process (ANP) and VIKOR (VIšekriterijumsko KOmpromisno Rangiranje) methods to evaluate various performance measures, such as applicability of workpiece material and shape 
features, process capabilities, and cost-related factors. Madić et al. (2015a) applied operational competitiveness rating analysis (OCRA) method as an MCDM tool for selection of the NTM processes from a large number of candidate alternatives. Saenz et al. (2015) proposed a novel method for selection and comparison of non-traditional sheet metal cutting processes. Khandekar \& Chakraborty (2016) applied fuzzy axiomatic design principles for selection of the most appropriate NTM processes for generating cavities on ceramics, and micro-holes on hardened tool steel and titanium materials. Chatterjee et al. (2017) presented a novel hybrid approach consisting of factor relationship (FARE) and multi-attributive border approximation area comparison (MABAC) methods for selection and evaluation of NTM processes. The FARE method was first applied to determine the corresponding criteria weights, and the alternative NTM processes are later ranked using MABAC method. Roy et al. (2017) proposed a combined application of fuzzy AHP and QFD methods for investigating the relative significance of different technical requirements in an NTM process selection approach, and also identified the suitability of electrochemical machining process for a specified industrial application. Prasad \& Chakraborty (2018) developed a decision guidance framework to assist the process engineers in choosing the most suitable NTM process for a given machining application and identifying the ideal process parameter settings for the said process. Yurdakul et al. (2019) presented intuitionistic and triangular fuzzy-based models for ranking of the suitable NTM processes for machining of some specific shape features on the given work materials. The performance of those models was later compared with that of crisp-based models. Amalnik (2019) proposed a feature-based expert system for optimization of design of an abrasive waterjet machining process. The corresponding database would consist of lists of 20 work materials, eight abrasive types and four machine types. The developed expert system would aid the process engineers while providing information with respect to machining cycle time, machining cost and cutting rate. Rohith et al. (2019) first adopted a data envelopment analysis (DEA)-based model for shorlisting the efficient NTM processes for a given shape feature and work material combination, and then employed AHP, TOPSIS and OCRA methods for ranking and selection of the efficient NTM processes. Yurdakul \& İç (2019) presented the applications of fuzzybased models of AHP and TOPSIS methods for NTM process selection for a particular work material and shape feature combinations. Talib and Asjad (2019) developed a model using AHP method for prioritizing as well as ranking of various NTM processes based on 27 evaluation criteria. Chakraborty et al. (2020) integrated rough numbers with MABAC method to identify the most feasible NTM processes for generation of standard through holes in glass and deep through cavities in titanium work materials. Based on firefly algorithm, Singh \& Shukla (2020) developed a graphical user interface for selecting the optimal input parameters for electrochemical machining, electrochemical micro-machining and electrochemical turning processes.

From an extensive review of the existing literature, it has been observed that varieties of expert systems have already been developed so as to help the process engineers in identifying the most competent NTM processes for different work material and shape feature combinations. Those developed expert systems have also been integrated with several other mathematical techniques, like AHP, ANP, TOPSIS, DEA, QFD etc. for arriving at the best courses of action. Those expert systems have been so designed and developed that they could only identify the most apposite NTM processes for varying machining applications. The expert system developed by Prasad \& Chakraborty (2018) could only advise the concerned process engineers about the tentative parametric settings of the chosen NTM processes, apart from selecting the most competent NTM processes to fulfil different application requirements. 
No research work has been carried out till date so as to predict the most probable values of various responses based on a given combination of different NTM process parameters or envisage the tentative settings of various NTM process parameters so as to achieve the most desired values of the considered responses. In this paper, an attempt is thus put forward so as to design and develop an intelligent decision model in Visual BASIC (VBASIC) that would help the process engineers in advising about the achievable values of different responses for a specific set of NTM process parameters or selecting the optimal parametric mix in order to attain a set of target responses. The developed system is supposed to be flexible and versatile enough as it encompasses all the available NTM processes, work materials and shape features, and also userfriendly and interactive as it always guides the end users in arriving at the optimal selection decision.

\section{Development of the Decision Model}

The procedural steps in the form of a flowchart in order to run this developed intelligent decision model without any error are exhibited in Figure 1.

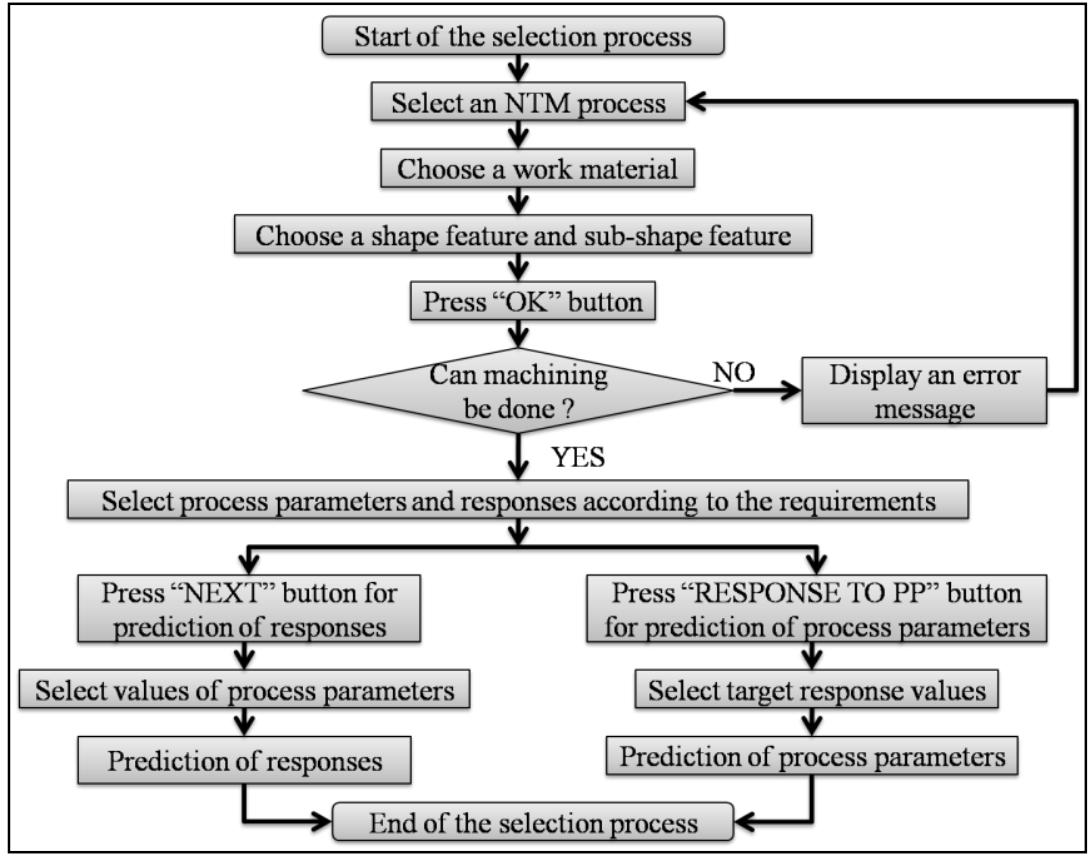

Figure 1. Flowchart exhibiting procedural steps of the developed decision model

At first, it would ask the end user to select the type of the NTM operation to be performed along with the combination of work material to be machined and shape/sub-shape feature to be generated. Once the NTM operation is specified, two lists containing the controllable parameters and responses associated with the selected NTM process would now appear in the next screen of the developed system. The end user would then be directed to preselect the machining parameters as available in that NTM process along with the set of desired responses in order to fulfil the end product requirements. The end user can also choose all the available NTM 198 
Development of an Intelligent Decision Model for Non-Traditional Machining Processes

process parameters and responses while pressing the 'SELECT ALL' functional key. It would then direct the end user to input the desired values of the identified NTM process parameters based on which the tentative values of the selected responses would be provided on pressing of the 'OK' button. Here, only the available values of the selected process parameters for a particular NTM process would appear in the screen in the form of drop-down menus. The reverse approach can also be augmented in this decision model while selecting the 'RESPONSE TO PP' functional key. The end user can also choose all the available NTM process parameters and responses while pressing the 'SELECT ALL' functional key, and select the 'RESPONSE TO PP' for having the tentative values of the NTM process parameters. It would then direct the end user to input the desired ranges of the identified NTM responses as beneficial and nonbeneficial criteria based on which the conditional values of the selected process parameters would be provided on pressing the 'OK' button. Here, only the available values of the selected responses for a particular NTM process would appear in the screen in the form of drop-down menu. If the end user opts for generating infeasible shape features or machining unsuitable materials using any of the considered NTM processes, an error message would appear indicating the incapability of that NTM process to generate the chosen shape feature on the given material. In this case, the end user has to repeat the procedural steps of NTM process selection from the beginning. In this paper, 17 NTM processes, i.e. (a) abrasive jet machining (AJM), (b) abrasive water jet machining (AWJM), (c) electron beam machining (EBM), (d) electrochemical grinding (ECG), (e) electrochemical machining (ECM), (f) electrochemical discharge machining (ECDM), (g) electro-discharge machining (EDM), (h) electro jet drilling (EJD), (i) focused ion beam machining (FIB), (j) hot chlorine machining (HM), (k) laser beam machining (LBM), (l) magnetorheological finishing (MRF), (m) plasma arc machining (PAM), (n) photochemical milling (PCM), (o) ultrasonic machining (USM), (p) wire electro-discharge machining (WEDM) and (q) water jet machining (WJM) are considered for subsequent development of the intelligent decision model. Similarly, the list of the considered work materials consists of (a) Alumina, (b) Aluminium, (c) Boron carbide, (d) Ceramics, (e) Composites, (f) Cemented tungsten carbide, (g) Duralumin, (h) Inorganic glass, (i) Inconel 718, (j) Inconel 800, (k) Inconel 825, (l) Incoloy, (m) Monel 400, (n) Monel K-500, (o) Nickel, (p) Nimonics, (q) Plastics, (r) Refractories, (s) Silicon nitride, (t) Silicon carbide, (u) Steel, (v) Stainless steel, (w) Titanium (ASTM Grade I), (x) Tungsten carbide and (y) Titanium-based super alloys. This system takes into consideration the following shape and sub-shape features for subsequent generation on the selected work material:

(a) Holes

(i) Precision holes ( $\mathrm{D} \leq 0.25 \mathrm{~mm}$ ) (where $\mathrm{D}=$ diameter)

(ii) Precision holes (D $>0.25 \mathrm{~mm}$ )

(iii) Standard holes (L/D $\leq 20)$ (where $\mathrm{L} / \mathrm{D}=$ length $/$ diameter $=$ slenderness ratio)

(b) Cavities

(iv) Standard holes (L/D > 20)

(i) Precision (aspect ratio $\leq 5$ )

(ii) Standard

(c) Surfacing

(i) Double contouring

(ii) Surface of revolution

(d) Through cutting

(i) Shallow (depth of cut $<40 \mu \mathrm{m}$ )

(ii) Deep (depth of cut $>40 \mu \mathrm{m}$ ) 
(e) Finishing.

The entire database containing the capabilities of all the considered NTM processes with respect to workpiece material, and shape and sub-shape features to be generated is stored in MS-ACCESS linked with VBASIC, and the decisions regarding values of various responses and settings of the NTM process parameters are arrived at based on sets of simple IF-THEN rules.

\section{Illustrative examples}

In order to demonstrate the applicability and usefulness of the developed decision model in the domain of NTM processes, the following three examples are cited.

\subsection{Example 1: Electro-discharge machining}

In this example, it is supposed that precision cavities with aspect ratio $\leq 5$ need to be generated on Inconel 718 alloy using EDM process. For this machining application, the corresponding input window in the form of a graphical user interface is shown in Figure 2.



Figure 2. Input window for the first example

Pressing of the 'OK' functional key then leads the end user to the next window, as exhibited in Figure 3, where the lists of all the important EDM process parameters, i.e. peak current, open circuit voltage, pulse-on time, duty factor, flushing pressure, pulseoff time, dielectric level, tool electrode lift time, polarity, type of the tool and flushing speed, and responses, like surface crack density, tool wear ratio (TWR), perpendicularity error (PE), material removal rate (MRR), surface roughness (SR), overcut (OC), electrode wear rate, edge deviation, white layer thickness and microharness are displayed. In this example, at first, the end user selects peak current, open circuit voltage, pulse-on time, duty factor, polarity and type of the tool as the controllable process parameters as available in the considered EDM set-up. On the other hand, based on the end product requirements, surface crack density, TWR, PE, MRR, SR and micro-hardness are treated with utmost importance. The end user can also choose all the EDM process parameters and responses while pressing the 'SELECT ALL' key. Now, when the 'NEXT' button is pressed, in the subsequent window, as depicted in Figure 4, the end user is opted to enter the appropriate values for the preselected EDM process parameters based on which the approximate values of the shortlisted responses would be predicted. In this example, the end user chooses the options as peak current $=9 \mathrm{~A}$, open circuit voltage $=60 \mathrm{~V}$, pulse-on time $=100 \mu \mathrm{s}$, duty factor $=70 \%$, polarity $=$ positive and tool material $=$ copper. Now, when the 'OK' button is pressed, this decision model would guide the end user to have an idea about various responses envisaged as surface crack density $=0.0055-0.0057 \mu \mathrm{m} / \mu \mathrm{m}^{2}$, MRR $=89.12-89.18 \mathrm{~mm}^{3} / \mathrm{min}, \mathrm{SR}=6.2-6.7 \mu \mathrm{m}, \mathrm{PE}=0.09-1.11 \%$, micro-hardness $=392.40$ $392.50 \mathrm{HV}$ and TWR $=0.0012-0.0016$. 
Development of an Intelligent Decision Model for Non-Traditional Machining Processes

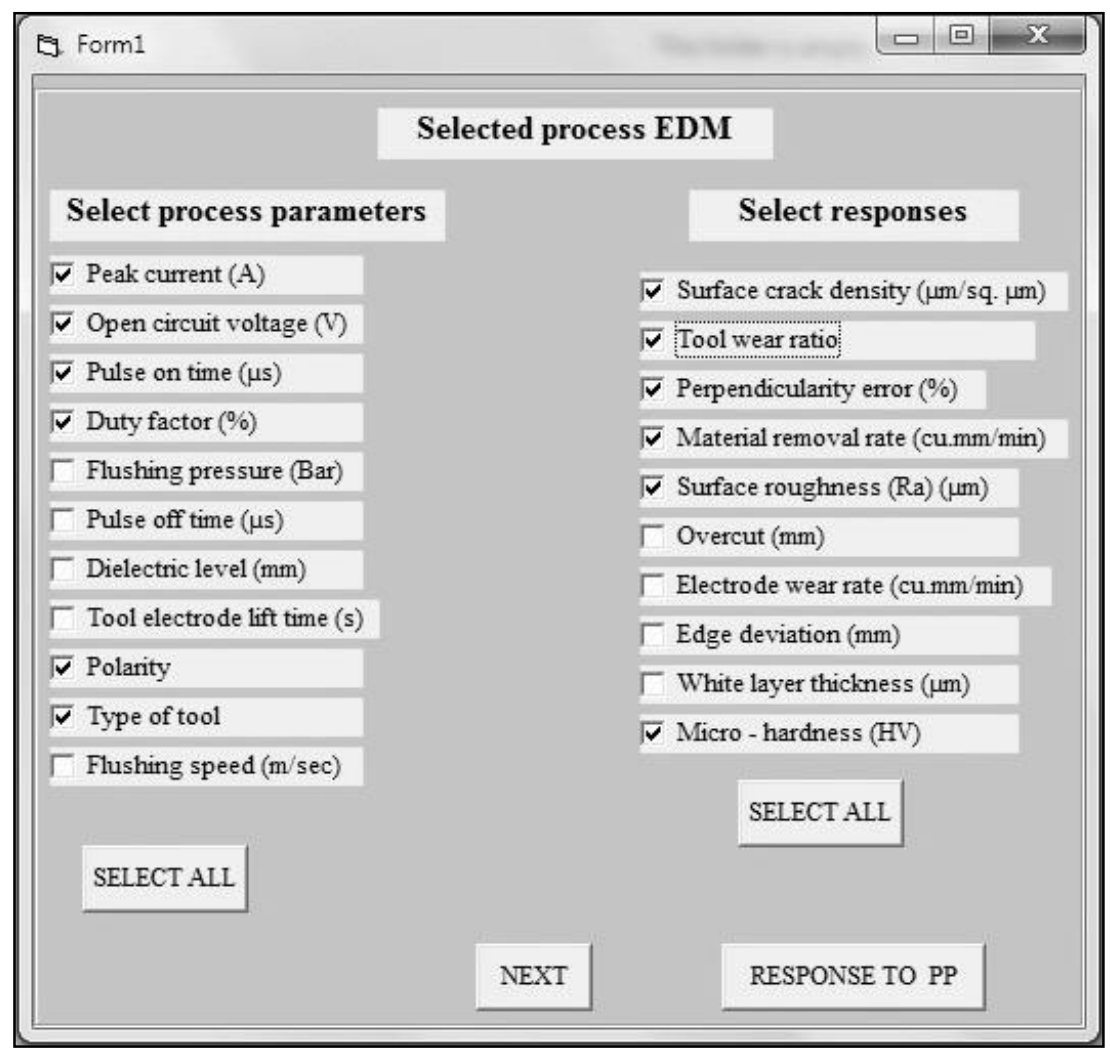

Figure 3. Window for selection of EDM process parameters and responses

In Figure 3, when the end user presses the 'RESPONSE TO PP' functional key, the settings of the preselected EDM process parameters can be predicted based on the chosen values of the shortlisted EDM responses. As exhibited in Figure 5, the end user desires to have high value of MRR (59.881-89.164 $\left.\mathrm{mm}^{3} / \mathrm{min}\right)$, and low values of electrode wear rate (0.011-0.059 $\left.\mathrm{mm}^{3} / \mathrm{min}\right)$, SR $(2.133-4.866 \mu \mathrm{m}), \mathrm{OC}(0.03-0.19$ $\mathrm{mm})$, surface crack density $\left(0.008-0.011 \mu \mathrm{m} / \mu \mathrm{m}^{2}\right)$, white layer thickness (16.646$17.866 \mu \mathrm{m})$ and micro-hardness (352.600-407.755 HV). Based on these input response values, the developed decision model predicts the related EDM process parameters as open circuit voltage $=47-50 \mathrm{~V}$, peak current $=10.5-11.5 \mathrm{~A}$, pulse-on time $=190-200 \mu \mathrm{s}$, duty factor $=78-82 \%$, flushing pressure $=0.15-0.25$ bar, type of the tool $=$ copper, polarity $=$ positive and pulse-off time $=25-35 \mu \mathrm{s}$. It is worthwhile to mention here that among the considered responses, material removal rate is the sole beneficial attribute requiring its higher value, whereas, lower values for the remaining non-beneficial responses are preferred. Based on the past experimental data on EDM processes (Ray, 2016; Datta et al., 2017), all the related response values are classified into three groups, i.e. low, medium and high so as to relieve the end user in providing an exact value for a specific response which may sometimes be a difficult task. According to the end product requirements, the end user can now be able to opt for only low, medium or high value for a particular response of interest. The derived parametric settings of the considered EDM process are only tentative. In order to achieve most accurate target values of the responses, fine-tuning of those parameters may often be needed. 
Chakraborty and Kumar/Decis. Mak. Appl. Manag. Eng. 4 (1) (2021) 194-214

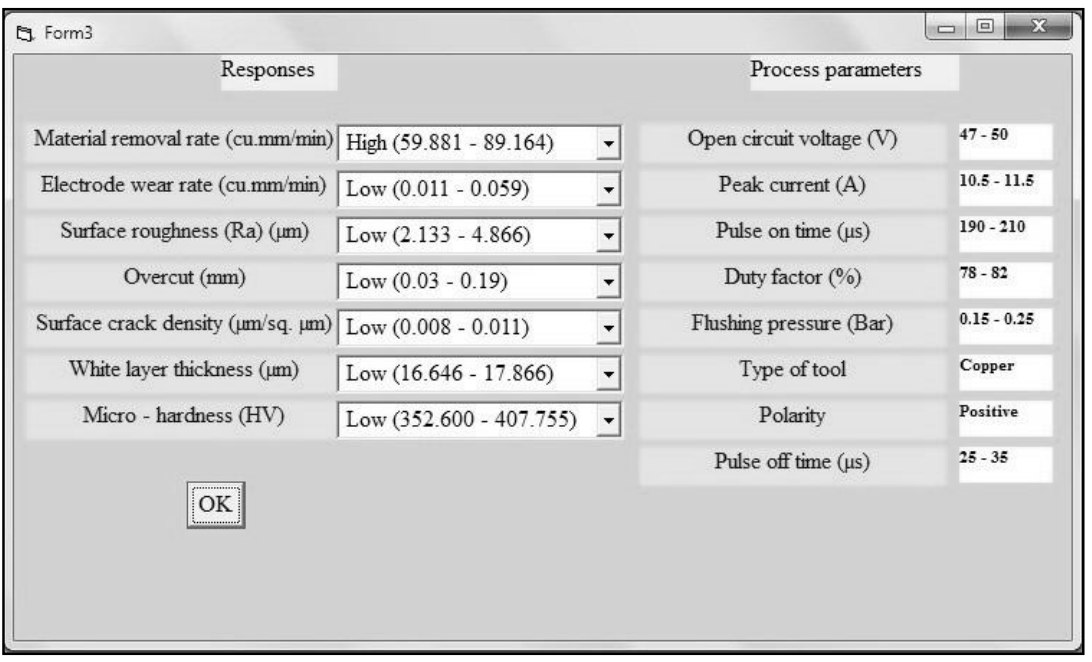

Figure 4. Prediction of responses based on EDM process parameters

\begin{tabular}{|c|c|c|c|c|}
\hline \multicolumn{3}{|l|}{ Form 3} & \multicolumn{2}{|c|}{\begin{tabular}{|l|l|l|} 
& 回 \\
\end{tabular}} \\
\hline Responses & & & Process parameters & \\
\hline Material removal rate (cu.mm/min) & High (59.881 - 89.164) & 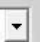 & Open circuit voltage (V) & $47-50$ \\
\hline Electrode wear rate (cu.mm/min) & Low $(0.011-0.059)$ & $\nabla$ & Peak current (A) & $10.5-11.5$ \\
\hline Surface roughness $(\mathrm{Ra})(\mu \mathrm{m})$ & Low $(2.133-4.866)$ & $\nabla$ & Pulse on time ( $\mu \mathrm{s})$ & $190-210$ \\
\hline Overcut (mm) & Low $(0.03-0.19)$ & 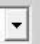 & Duty factor (\%) & $78-82$ \\
\hline Surface crack density ( $\mu \mathrm{m} / \mathrm{sq} . \mu \mathrm{m})$ & Low $(0.008-0.011)$ & 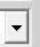 & Flushing pressure (Bar) & $0.15-0.25$ \\
\hline White layer thickness $(\mu \mathrm{m})$ & Low (16.646 - 17.866) & 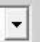 & Type of tool & Copper \\
\hline \multirow[t]{2}{*}{ Micro - hardness (HV) } & Low (352.600 - 407.755) & $\nabla$ & Polarity & Positive \\
\hline & & & Pulse off time ( $\mu \mathrm{s})$ & $25-35$ \\
\hline \multicolumn{5}{|l|}{ OK } \\
\hline
\end{tabular}

Figure 5. Prediction of EDM process parameters based on the responses

In Figure 6, when the end user opts for performing deep through cutting operation (depth of cut $>40 \mu \mathrm{m}$ ) on ceramic materials using the EDM process, an error message would appear indicating the incapability of EDM process to generate the chosen shape feature on ceramics. It can be interestingly noticed that with increasing values of all the EDM process parameters, MRR would also increase. Higher values of gap voltage, peak current and pulse-on time are all responsible for the available discharge energy to increase, resulting in more melting and vaporization of material from the workpiece. The impulsive force in the spark gap also increases, which is responsible for higher MRR (Gopalakannan et. al., 2012). Increments in gap voltage and peak current generate stronger discharge energy, creating higher temperature and formation of larger craters on the machined surface, resulting in poor surface quality (Kiyak \& Çakır, 2007) Similarly, TWR increases with higher values of gap voltage, peak current and cycle time. At these higher parametric settings, there are micro tool wears 
Development of an Intelligent Decision Model for Non-Traditional Machining Processes

due to availability of higher spark energy density at the machining zone. Generally, lower settings of these EDM process parameters tend to enhance the possibility of carbon deposition on the tool surface, which finally helps in lowering TWR value (Lin \& Lee., 2008). The PE in the machined components occurs due to non-uniform undercut and $\mathrm{OC}$ which can be effectively controlled by proper settings of different EDM process parameters. With increasing values of gap voltage and peak current, PE shows an increasing trend. At higher gap voltage and peak current, there are occurrences of secondary spark discharges caused by poor flushing as well as sporadic machining which are responsible for inferior PE. During EDM operation, OC occurs due to side erosion and removal of debris. At higher settings of voltage, peak current and pulse-on time, availability of higher gap voltage and gap width allows breakdown of the dielectric at a wider gap due to higher electric field. At higher gap voltage and peak current, spark energy density would be more with a faster machining rate, which is also responsible for higher OC. Hence, the predicted parametric intermix for the EDM process would minimize the $\mathrm{OC}$ of the machined components. The above parametric setting can also be validated based on the observations of the past researchers (Ray, 2016; Prasad \& Chakraborty, 2018).

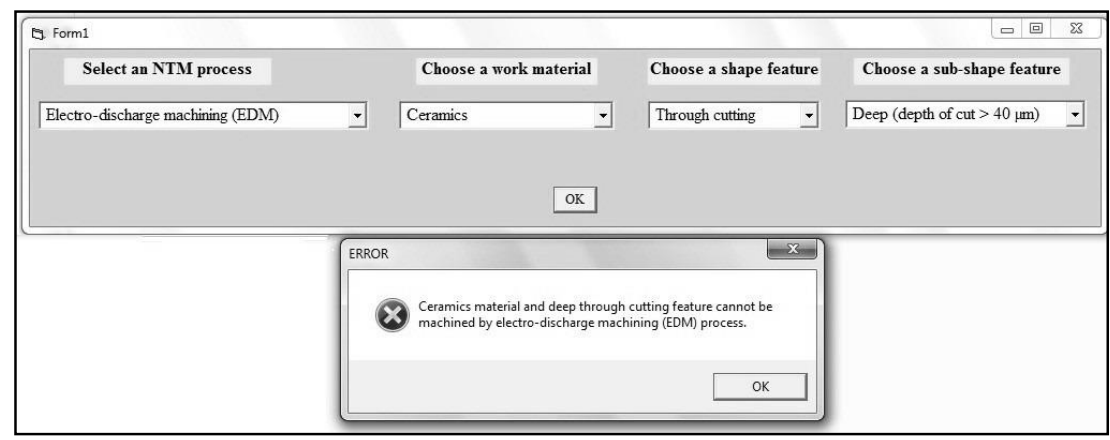

Figure 6. An error message for EDM process

\subsection{Example 2: Ultrasonic machining}

Here, the end user desires to generate standard holes with slenderness ratio of less than equal to 20 on Titanium (ASTM Grade I) work material while utilizing USM process. Figure 7 exhibits the input window for this example. In Figure 8, from a list of the available controllable parameters for the USM process, type of the abrasive material, abrasive grit size, amplitude of vibration, machining time, type of the tool material, power rating and slurry concentration are first shortlisted. On the other hand, conicity, MRR, SR, tool wear rate (TW) and micro-harness are opted as the important responses. Depending on the requirements, the entire lists for the available USM process parameters and responses can also be selected. The entire information related to these USM process parameters and responses are accumulated from (Kumar \& Khamba, 2010; Kataria et al., 2017). 
Chakraborty and Kumar/Decis. Mak. Appl. Manag. Eng. 4 (1) (2021) 194-214

\begin{tabular}{|c|c|c|c|c|c|c|c|}
\hline form1 & & & & & & \multicolumn{2}{|c|}{ 밀 } \\
\hline \multicolumn{2}{|l|}{ Select an NTM process } & \multicolumn{2}{|c|}{ Choose a work material } & \multicolumn{2}{|c|}{ Choose a shape feature } & \multicolumn{2}{|c|}{ Choose a sub-shape feature } \\
\hline Ultrasonic machining (USM) & 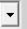 & Ceramics & $\nabla$ & Holes & $\nabla$ & Standard holes $(L / D<20)$ & $\nabla$ \\
\hline & & & & & & & \\
\hline
\end{tabular}

Figure 7. Input window for example 2

Now, in Figure 8, when the 'NEXT' functional key is pressed, the developed decision model would seek for the values of the shortlisted USM process parameters in another window, as portrayed in Figure 9.

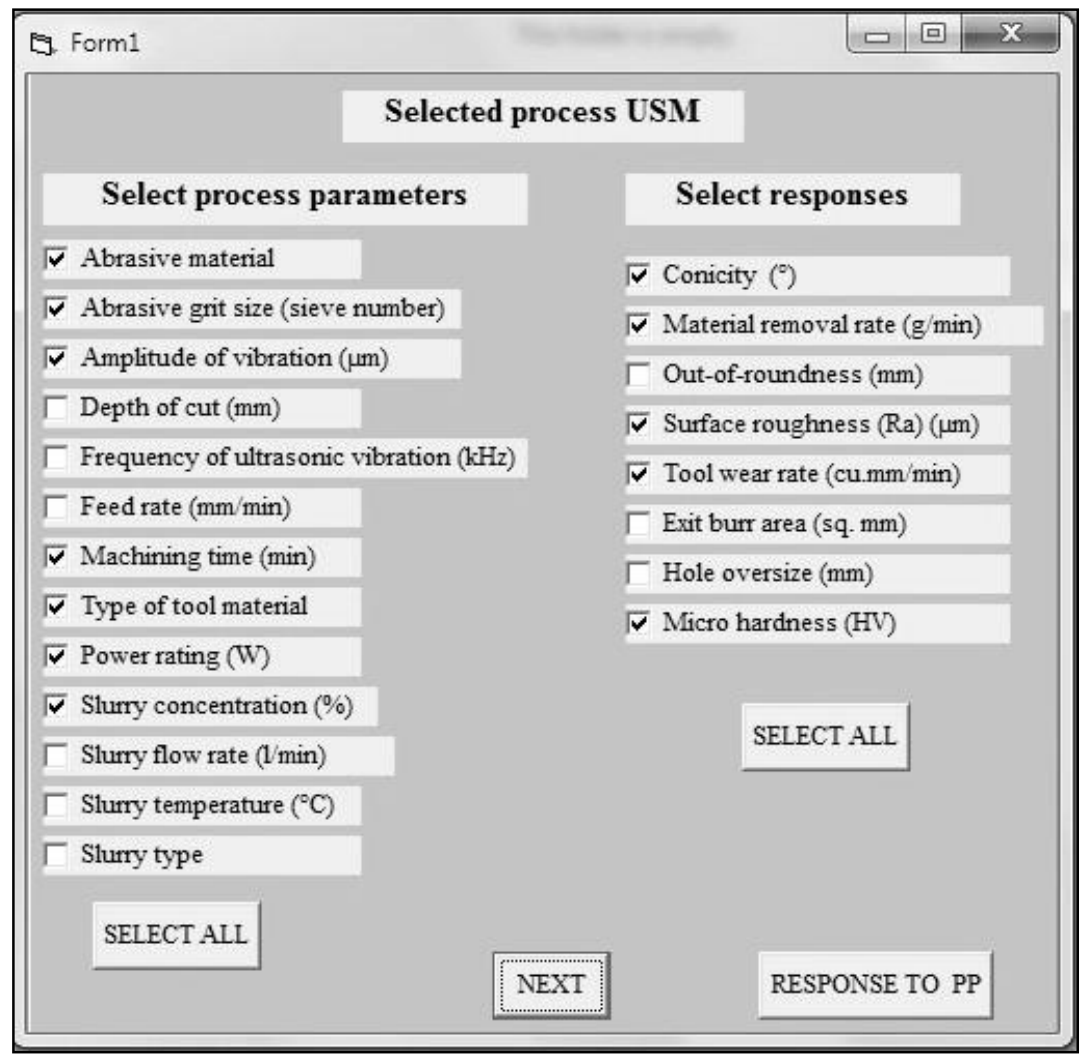

Figure 8. Window for selection of USM process parameters and responses

In this case, the end user chooses the values of different USM parameters as type of the abrasive material $=$ Boron carbide, abrasive grit size $=280$, amplitude of vibration $=25 \mu \mathrm{m}$, machining time $=8.70 \mathrm{~min}$, type of the tool material $=$ Tungsten carbide, power rating $=550 \mathrm{~W}$ and slurry concentration $=45 \%$. The drop-down menu attached with each of the process parameters guides the user to opt for the most apposite value as available in a particular USM set-up. 
Development of an Intelligent Decision Model for Non-Traditional Machining Processes

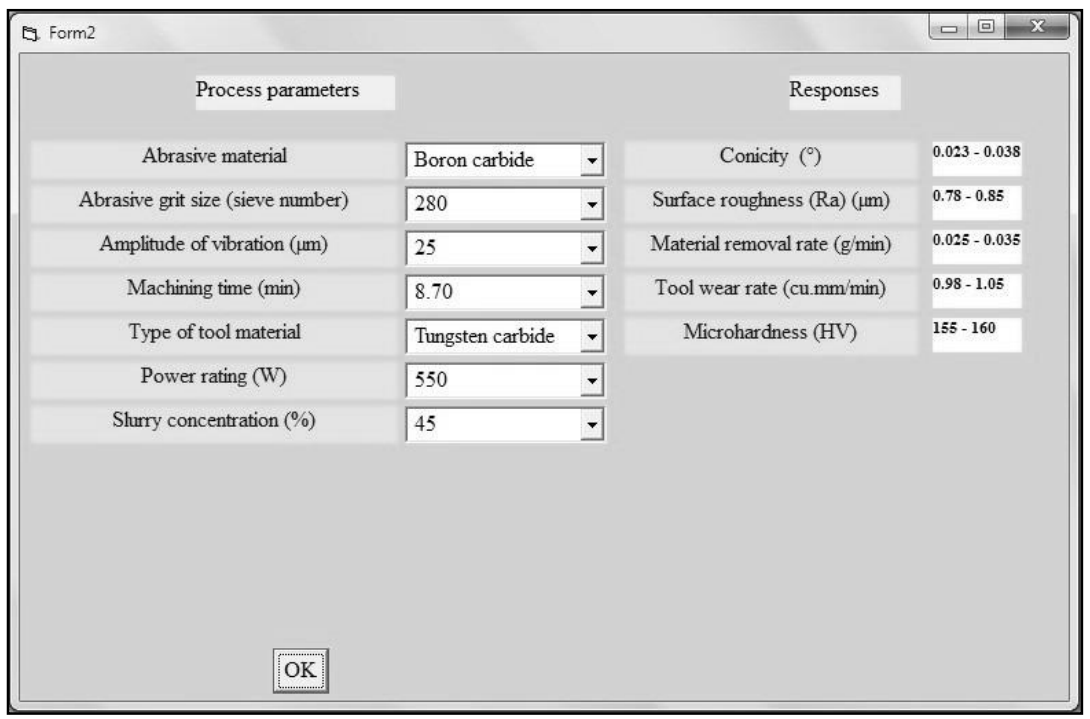

Figure 9. Prediction of responses based on USM process parameters

Based on these requirements, the developed system predicts the responses as conicity $=0.023-0.038^{\circ}, \mathrm{SR}=0.78-0.85 \mu \mathrm{m}, \mathrm{MRR}=0.025-0.035 \mathrm{~mm}^{3} / \mathrm{min}, \mathrm{TW}=0.98-$ $1.05 \mathrm{~mm}^{3} / \mathrm{min}$ and micro-hardness $=155-160 \mathrm{HV}$. Now, when the 'RESPONSE TO PP' functional key is pressed in Figure 8, this system would jump to a new window, as shown in Figure 10, where the end user is asked to input the desired values of the preselected responses in order to guide him/her about the tentative settings of different USM process parameters.

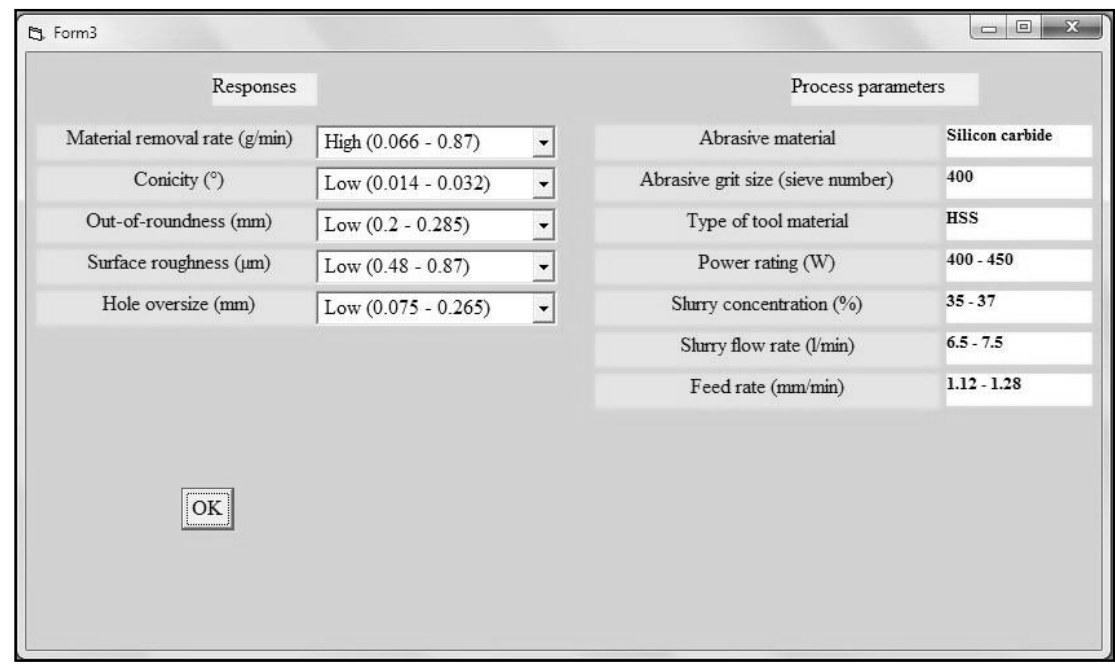

Figure 10. Prediction of USM process parameters based on the responses

Here, high value of MRR $\left(0.066-0.870 \mathrm{~mm}^{3} / \mathrm{min}\right)$, and low values for conicity (0.014-0.032 $\left.{ }^{\circ}\right)$, out-of-roundness (0.200-0.285 mm), SR (0.48-0.87 $\left.\mu \mathrm{m}\right)$ and hole oversize $(0.075-0.265 \mathrm{~mm})$ are sought by the end user. Depending on these requirements, it advises the user to set the corresponding USM parameters as type of 
the abrasive material $=$ Silicon carbide, abrasive grit size $=400$, type of the tool material $=\mathrm{HSS}$, power rating $=400-450 \mathrm{~W}$, slurry concentration $=35-37 \%$, slurry flow rate $=6.5-7.5 \mathrm{l} / \mathrm{min}$ and feed rate $=1.12-1.28 \mathrm{~mm} / \mathrm{min}$. In order to achieve more accurate machining performance, fine-tuning of the settings of the considered USM process parameters may often be required. When the end user chooses the same USM process for generation of precision holes ( $\mathrm{D} \leq 0.25 \mathrm{~mm}$ ) to be machined on Aluminium work material, an error message, as shown in Figure 11, would automatically be generated by the system indicating the fact that it cannot machine precision holes on Aluminium material.

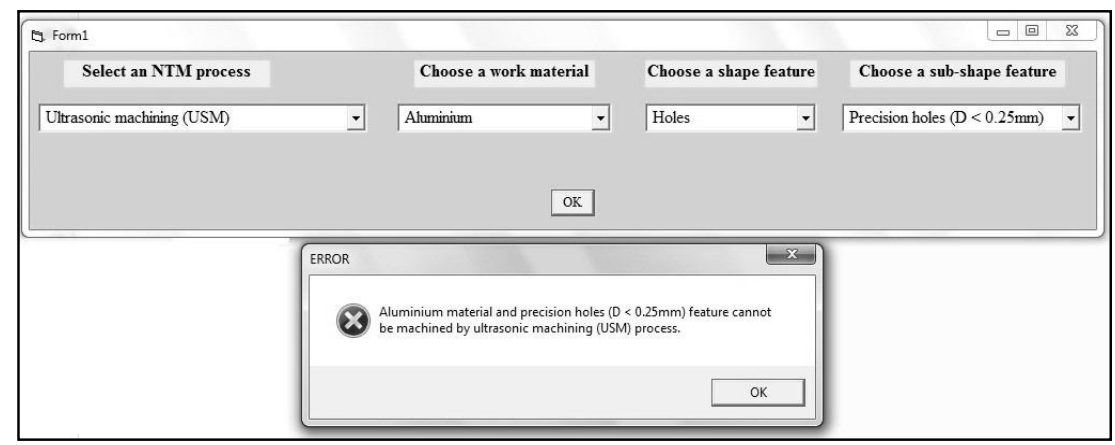

Figure 11. A typical error message for USM process

In USM process, when the amplitude of vibration increases, energy at the tool tip also increases, resulting in higher SR due to increased impact of the abrasive particles on the workpiece. Furthermore, TW also increases due to increase in the slurry flow rate containing harder abrasive particles, which are bombarded on the tool tip. The cavitation effects also lead to an increase in TW. With increase in amplitude of vibration, there is an increment in MRR as higher amplitude attributes to higher momentum imparted to the abrasive particles before striking the workpiece. It raises the energy with which the abrasive particles collide on the work surface and hence, the micro-crack or micro-crater created by each impact facilitates the material removal process. On the other hand, MRR decreases because the successive impacts between the abrasive grains and the work material may lead to large amount of plastic deformation resulting in the formation of a work-hardened layer, causing reduction in MRR (Bhosale et al., 2014). An increment in slurry concentration is responsible for more impact on the work surface leading to higher SR. This also causes an increase in TW since more abrasive particles come into contact with the tool over a given period of time. However, the material removal tendency decreases because of the loss of energy possessed by the abrasives in the slurry. As the number of particles between the tool and the work surface increases due to higher slurry concentration, loss of energy due to interparticle collision may prevail during this phenomenon (Kataria et al., 2017; Chakraborty et al., 2020).

\subsection{Example 3: Plasma arc machining}

In this example, deep through cutting operation with depth of cut $>40 \mu$ m needs to be performed on a workpiece made of stainless steel using PAM process. In order to satisfy these requirements, the corresponding NTM process, work material, shape feature and sub-shape feature are accordingly selected in Figure 12. 
Development of an Intelligent Decision Model for Non-Traditional Machining Processes

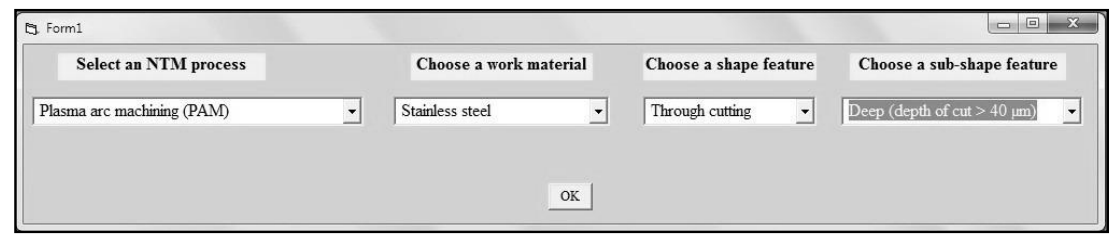

Figure 12. Input window for example 3

For the PAM process, based on an extensive survey of the existing literature (Xu et al., 2002; Das et al., 2014; Adalarasan et al., 2015; Ramakrishnan et al., 2018), arc voltage, cutting current, cutting speed, feed rate, torch stand-off distance, plasma gas pressure and pierce height are identified as the predominant control parameters influencing its machining performance. On the other hand, the important responses are shortlisted as conicity, chamfer, dross, heat affected zone (HAZ), kerf width, MRR and SR. Now, in Figure 13, the end user preselects arc voltage, cutting current, feed rate and torch stand-off distance as the available PAM process parameters, and chamfer, dross, kerf width and SR as the desired responses.

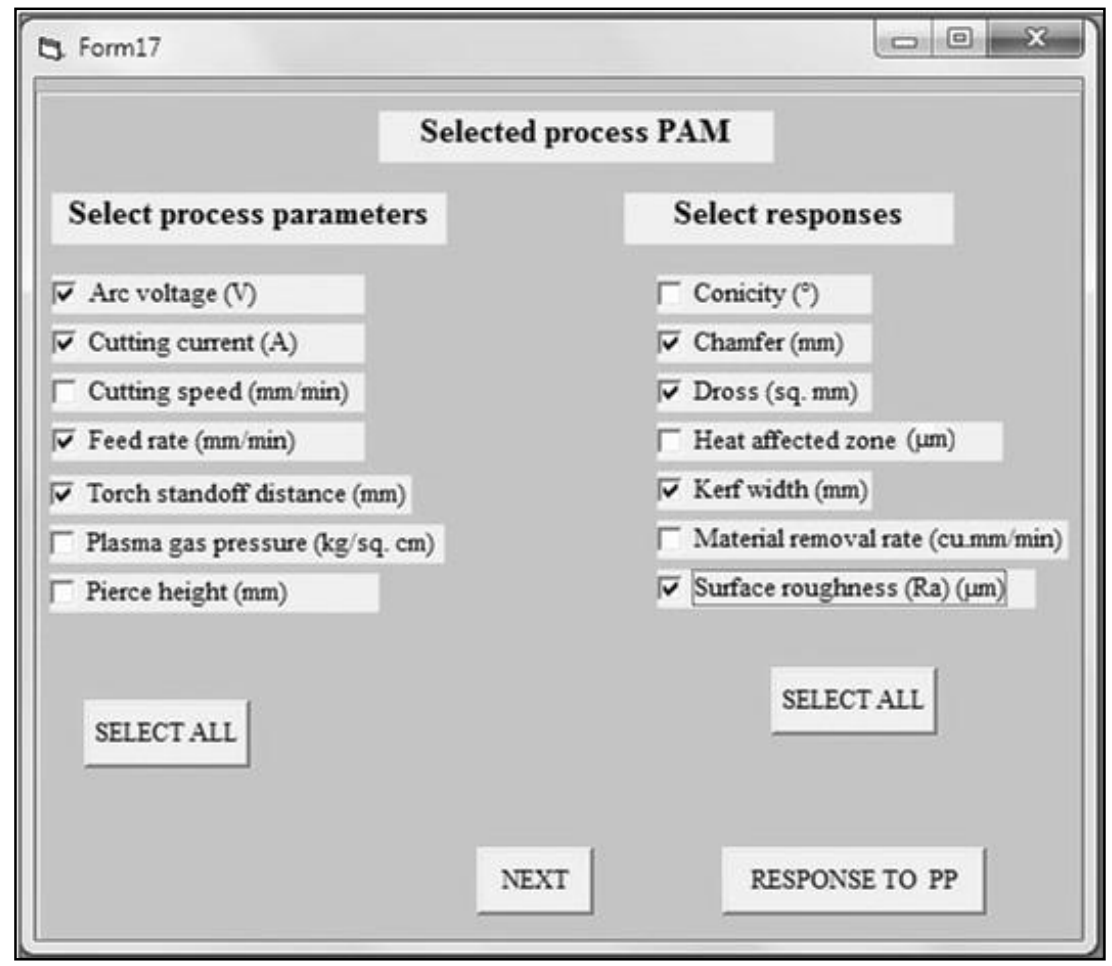

Figure 13. Window for selection of PAM process parameters and responses

The values of these four shortlisted PAM process parameters are set as arc voltage $=120 \mathrm{~V}$, cutting current $=42.5 \mathrm{~A}$, feed rate $=945 \mathrm{~mm} / \mathrm{min}$ and torch stand-off distance $=2.5 \mathrm{~mm}$, as exhibited in Figure 14. Based on this parametric combination, the developed decision model predicts the shortlisted responses as chamfer $=1.80-1.85$ $\mathrm{mm}$, dross $=3.60-3.64 \mathrm{~mm}^{2}$, kerf width $=2.70-2.75 \mathrm{~mm}$ and $\mathrm{SR}=0.76-0.85 \mu \mathrm{m}$. Thus, 
this system would help the process engineers to have an idea about the achievable values of different responses based on a preselected set of parametric combinations.

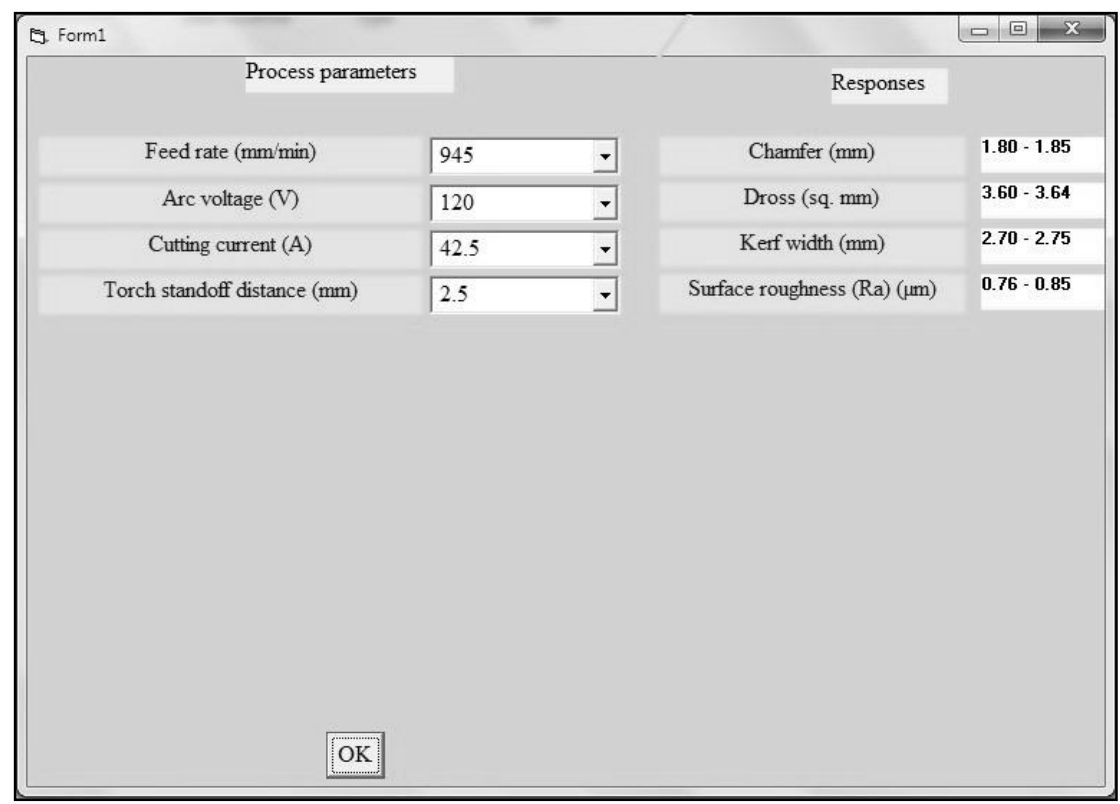

Figure 14. Prediction of responses based on PAM process parameters

In Figure 13, if the end user presses the 'RESPONSE TO PP' functional key, a new input window, as shown in Figure 15, would now be available where the ranges of values for different responses can be set according to the end product requirements. In this example, the end user opts for high value of MRR $\left(2.06-2.80 \mathrm{~mm}^{3} / \mathrm{min}\right)$, and low values for conicity (0.009-0.021을 dross (0.45-3.49 $\left.\mathrm{mm}^{2}\right)$, kerf width (1.93-2.53 mm) and SR (0.724-0.875 $\left.\mu \mathrm{m}\right)$. Now, based on these response requirements, the developed system would advise the process engineer to set different parameters of the PAM process as feed rate $=930$ $950 \mathrm{~mm} / \mathrm{min}$, cutting speed $=2260-2280 \mathrm{~mm} / \mathrm{min}$, plasma gas pressure $=4.57-4.92$ $\mathrm{kg} / \mathrm{cm}^{2}$, arc voltage $=115-125 \mathrm{~V}$ and torch stand-off distance $=2.5-4.5 \mathrm{~mm}$. These are only the tentative settings of the considered PAM setup. The process engineer may require to fine-tune these settings in order to achieve more accurate results. 
Development of an Intelligent Decision Model for Non-Traditional Machining Processes

\begin{tabular}{|c|c|c|c|c|}
\hline \multicolumn{4}{|l|}{ Q form19 } & \multirow[t]{2}{*}{ 回回 } \\
\hline \multicolumn{2}{|c|}{ Responses } & \multicolumn{2}{|r|}{ Process parameters } & \\
\hline Conicity $\left({ }^{\circ}\right)$ & Low $(0.009-0.021)$ & $\nabla$ & Feed rate (mm/min) & $930-950$ \\
\hline Heat affected zone $(\mu \mathrm{m})$ & Low $(325-400)$ & $\nabla$ & Cutting speed (mm/min) & $2260-2280$ \\
\hline Chamfer (mm) & Low $(1.00-1.32)$ & 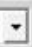 & Plasma gas pressure $(\mathrm{kg} / \mathrm{sq} . \mathrm{cm})$ & $4.57 \cdot 4.92$ \\
\hline Dross (sq. mm) & Low $(0.45-3.49)$ & $\nabla$ & Arc voltage $(V)$ & $115-125$ \\
\hline Kerf width (mm) & Low (1.93-2.53) & 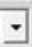 & Torch standoff distance $(\mathrm{mm})$ & $2.5-4.5$ \\
\hline Material removal rate (cu mm/min) & 1) High (2.06 - 2.80) & $\nabla$ & & \\
\hline Surface roughness $(\mathrm{Ra})(\mu \mathrm{m})$ & Low $(0.724-0.875)$ & $\neg$ & & \\
\hline
\end{tabular}

Figure 15. Prediction of PAM process parameters based on the responses

As shown in Figure 16, when the end user wants to machine precision holes on refractories using the available PAM process, the system would automatically generate an error message highlighting its inability to machine the specified work material.

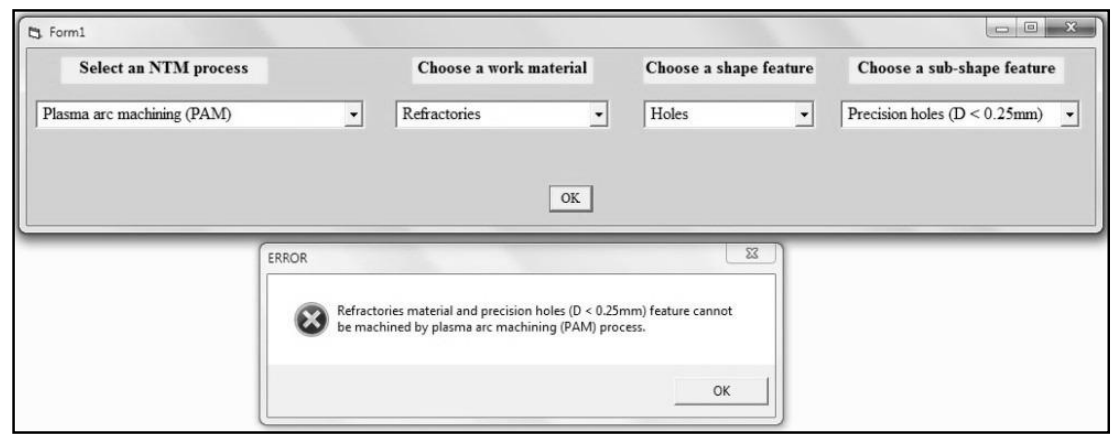

Figure 16. An error message for PAM process

In PAM process, torch stand-off distance has the strongest effect on the quality characteristics. Stand-off distance is one of the crucial parameters in PAM process as it controls SR and conicity of the cut edge. It has also been observed that cutting current also influences the HAZ of the cut edge. It greatly influences SR of the cut due to the fact that the plasma gas beam is not of cylindrical shape but resembles the shape of a reversed candle flame. Therefore, depending on the relative position of the plasma to the workpiece surface, the surface quality is drastically affected due to thermal properties of the material (Salonitis \& Vatousianos, 2012). The MRR increases with an increase in gas pressure and high gas flow because it leads to an increase in mean arc voltage and its fluctuations as more heat is transferred into the workpiece, and 
consequently, SR reduces. However, MRR remains constant with an increase in standoff distance as there is a slight fluctuation in energy. For higher plasma gas flow rate, arc voltage also becomes higher. As the gas flow rate increases, more energy is needed to ionize the gas, therefore the arc voltage should be higher. The kerf is narrower at the top, it widens at the middle, and again becomes narrower at the bottom, making heat distribution along the cut to be irregular. During PAM operation, dross formation at the bottom of the workpiece needs to be minimized while controlling the corresponding process parameters. At low speed, input energy to the workpiece is high, causing melting of more materials. Dross is formed when adequate force of the plasma jet is not available. To obtain a dross-free cut surface, plasma force and energy input to the workpiece need to be balanced properly. Plasma power increases with plasma gas flow rate and arc current. To achieve a square cut of narrow kerf with minimal dross, the decision model can efficiently predict the tentative ranges of the process parameters (Mittal \& Mahajan, 2018). The same parametric combination for the PAM process is also well derived by the past researchers (Ramakrishnan et al., 2018; Prasad \& Chakraborty, 2018; Chakraborty et al., 2020).

\section{Conclusions}

In this paper, an attempt is made to design and develop an intelligent decision model in VBASIC so as to help the concerned process engineers in the domain of NTM processes. Based on the availability of a particular NTM process, and selected workpiece and shape feature combination, it can identify values of different responses for a given set of parametric combinations. On the other hand, it has also the capability of predicting the tentative settings of different NTM process parameters while meeting the specified values of a given set of responses. In this system, the decision making procedure is based on an exhaustive set of IF-THEN rules, and it consists of all the possible combinations of different NTM processes, work materials and shape features. It is easy to operate as the graphical user interface continuously interacts with the end users restricting them to commit any error. It has also the flexibility to cater any combination of NTM process, work material and shape feature. It warns the end user when a particular machining operation cannot be performed by a specific NTM process. The developed decision model assists the process engineers and designers to efficiently identify the technically feasible NTM processes in the early design and machining stages, enabling in developing the required product functionalities and appearance with the feasible processes in mind, while utilizing the process characteristics more effectively. After the detailed design is complete, the feasible processes identified in the earlier steps can be reevaluated, reassessing their technical feasibilities for manufacturing the designed product. The design can also be modified accordingly, if needed, to ensure manufacturability of the product. The main advantage of this decision model is that it does not require any in-depth technical knowledge regarding the applicability of the NTM processes. It also acts as an expert system to ease out and automate the NTM process selection procedure.

This decision model has also some limitations. Firstly, it does not take into account the presently available hybrid machining and additive manufacturing processes. Moreover, it is developed based on a static database. It would be worth investigating the possibility of integrating the decision model into the 'cloud' under the Industry 4.0 context, allowing prompt feedback and rapid update. It is also assumed that the developed decision model has no maintenance and operation costs. It lacks the creative responses of the human experts, and is also not able to explain the logic and 
Development of an Intelligent Decision Model for Non-Traditional Machining Processes reasoning behind a decision to the end user. It opens opportunities to include micromachining, hybrid machining and additive manufacturing technology selection modules as well as improving selection results while incorporating more selection criteria and work materials in the model. It is expected that the developed model would be well accepted by the manufacturing industries for arriving at the prompt NTM process selection decisions. It can also be implemented in a group decision making environment involving opinions of different process engineers having varying background knowledge and expertise for more pragmatic results. Its capability, reach and usability may further be enhanced while making it entirely web-based to become accessible to its end users through an internet network.

Author Contributions: Each author has participated and contributed sufficiently to take public responsibility for appropriate portions of the content.

Funding: This research received no external funding.

Conflicts of Interest: The authors declare no conflicts of interest.

\section{References}

Adalarasan, R., Santhanakumar, M., \& Rajmohan, M. (2015). Application of grey Taguchi-based response surface methodology (GT-RSM) for optimizing the plasma arc cutting parameters of $304 \mathrm{~L}$ stainless steel. International Journal of Advanced Manufacturing Technology, 78(5-8), 1161-1170.

Amalnik, M.S. (2019). Design and manufacturing optimization of abrasive water jet machining using expert system. International Journal of Advanced Design and Manufacturing Technology, 12(1), 101-114

Azaryoon, A., Hamidon, M., \& Radwan, A. (2015). An expert system based on a hybrid multi-criteria decision making method for selection of non-conventional machining processes. In Applied Mechanics and Materials, Trans Tech Publications Ltd., 735, 4149.

Bhosale, S.B., Pawade, R.S., \& Brahmankar, P.K. (2014) Effect of process parameters on MRR, TWR and surface topography in ultrasonic machining of alumina-zirconia ceramic composite. Ceramics International, 40(8), 12831-12836.

Chakladar, N.D., \& Chakraborty, S. (2008). A combined TOPSIS-AHP-method-based approach for non-traditional machining processes selection. Proceedings of the Institution of Mechanical Engineers, Part B: Journal of Engineering Manufacture, 222(12), 1613-1623.

Chakladar, N.D., Das, R., \& Chakraborty, S. (2009). A digraph-based expert system for non-traditional machining processes selection. International Journal of Advanced Manufacturing Technology, 43(3), 226-237.

Chakraborty, S., \& Dey, S. (2006). Design of an analytic-hierarchy-process-based expert system for non-traditional machining process selection. International Journal of Advanced Manufacturing Technology, 31(5-6), 490-500.

Chakraborty, S., \& Dey, S. (2007). QFD-based expert system for non-traditional machining processes selection. Expert Systems with Applications, 32(4), 1208-1217. 
Chakraborty, S., Dandge, S.S., \& Agarwal, S. (2020). Non-traditional machining processes selection and evaluation: A rough multi-attributive border approximation area comparison approach. Computers \& Industrial Engineering, 139, 106-201.

Chandraseelan, E.R., Jehadeesan, R., \& Raajenthiren, M. (2008). Web-based knowledge based system for selection of non-traditional machining processes. Malaysian Journal of Computer Science, 21(1), 45-56.

Chatterjee, P., Mondal, S., Boral, S., Banerjee, A., \& Chakraborty, S. (2017). A novel hybrid method for non-traditional machining process selection using factor relationship and multi-attributive border approximation method. Facta Universitatis, Series: Mechanical Engineering, 15(3), 439-456.

Das, M.K., Kumar, K., Barman, T.K., \& Sahoo, P. (2014). Optimization of process parameters in plasma arc cutting of EN31 steel based on MRR and multiple roughness characteristics using grey relational analysis. Procedia Materials Science, 5, 15501559.

Datta, S., Biswal, B.B., \& Mahapatra, S.S. (2017). A novel satisfaction function and distance-based approach for machining performance optimization during electrodischarge machining on super alloy Inconel 718. Arabian Journal for Science and Engineering, 42(5), 1999-2020.

El-Hofy, H. (2005). Advanced Machining Processes: Nontraditional and Hybrid Machining Processes. McGraw Hill Professional, USA.

Gopalakannan, S., Senthivelan, T., \& Ranganathan, S. (2012). Modeling and optimization of EDM process parameters on machining of Al7075- ${ }_{4} \mathrm{C}$ MMC using RSM, Procedia Engineering, 38(1), 685-690.

Jain, V.K. (1980). Advanced Machining Processes. Allied publishers Pvt. Ltd., India.

Karande, P., \& Chakraborty, S. (2012). Application of PROMETHEE-GAIA method for non-traditional machining processes selection. Management Science Letters, 2(6), 2049-2060.

Kataria, R., Kumar, J., \& Pabla, B.S. (2017). Ultrasonic machining of WC-Co composite material: Experimental investigation and optimization using statistical techniques. Proceedings of the Institution of Mechanical Engineers, Part B: Journal of Engineering Manufacture, 231(5), 867-880.

Khandekar, A.V., \& Chakraborty, S. (2016). Application of fuzzy axiomatic design principles for selection of non-traditional machining processes. International Journal of Advanced Manufacturing Technology, 83(1-4), 529-543.

Kiyak, M., \& Çakır, O. (2007). Examination of machining parameters on surface roughness in EDM of tool steel. Journal of Materials Processing Technology, 191(1-3), 141-144.

Kumar, J., \& Khamba, J.S. (2010). Multi-response optimisation in ultrasonic machining of titanium using Taguchi's approach and utility concept. International Journal of Manufacturing Research, 5(2), 139-160.

Lin, Y.C., \& Lee, H.S. (2008). Machining characteristics of magnetic force-assisted EDM. International Journal of Machine Tools and Manufacture, 48(11), 1179-1186. 
Development of an Intelligent Decision Model for Non-Traditional Machining Processes

Madić, M., Petković, D., \& Radovanović, M. (2015a). Selection of non-conventional machining processes using the OCRA method. Serbian Journal of Management, 10(1), 61-73.

Madić, M., Radovanović, M., \& Petković, D. (2015b). Non-conventional machining processes selection using multi-objective optimization on the basis of ratio analysis method. Journal of Engineering Science and Technology, 10(11), 1441-1452.

Mittal, S., \& Mahajan, M.D. (2018). Multi-response parameter optimization of CNC plasma arc machining using Taguchi methodology. Industrial Engineering Journal, 11(12), 1550-1559.

Pandey, P.C., \& Shan, H.S. (1980). Modern Machining Processes. Tata McGraw-Hill Education, India.

Prasad, K., \& Chakraborty, S. (2018). A decision guidance framework for nontraditional machining processes selection. Ain Shams Engineering Journal, 9(2), $203-$ 214.

Rajurkar, K.P., Hadidi, H., Pariti, J., \& Reddy, G.C. (2017). Review of sustainability issues in non-traditional machining processes. Procedia Manufacturing, 7, 714-720.

Ramakrishnan, H., Balasundaram, R., Ganesh, N., \& Karthikeyan, N. (2018). Experimental investigation of cut quality characteristics on SS321 using plasma arc cutting. Journal of the Brazilian Society of Mechanical Sciences and Engineering, 40(60), 1-11.

Ray, A. (2016). Optimization of process parameters of green electrical discharge machining using principal component analysis (PCA). International Journal of Advanced Manufacturing Technology, 87(5-8), 1299-1311.

Rohith, R., Shreyas, B.K., Kartikgeyan, S., Sachin, B.A., Umesha, K.R., \& Nanjundeswaraswamy, T.S. (2019). Selection of non-traditional machining process. International Journal of Engineering Research \& Technology, 8(11), 148-155.

Roy, M.K., Ray, A., \& Pradhan, B.B. (2014). Non-traditional machining process selection using integrated fuzzy AHP and QFD techniques: A customer perspective. Production \& Manufacturing Research, 2(1), 530-549.

Roy, M.K., Ray, A., \& Pradhan, B.B. (2017). Non-traditional machining process selection - An integrated approach. International Journal for Quality Research, 11(1), 71-94.

Saenz, D.C., Castillo, N.G., Romeva, C.R., \& Macia, J.L. (2015). A fuzzy approach for the selection of non-traditional sheet metal cutting processes. Expert Systems with Applications, 42(15), 6147-6154.

Salonitis, K., \& Vatousianos, S. (2012). Experimental investigation of the plasma arc cutting process. Procedia CIRP, 3(1), 287-292.

Sarkar, A., Panja, S.C., Das, D., \& Sarkar, B. (2015). Developing an efficient decision support system for non-traditional machine selection: An application of MOORA and MOOSRA. Production \& Manufacturing Research, 3(1), 324-342.

Singh, D., \& Shukla, R.S. (2020). Development of firefly algorithm interface for parameter optimization of electrochemical-based machining processes. In Applications of Firefly Algorithm and its Variants, Springer, Singapore, 29-52. 
Chakraborty and Kumar/Decis. Mak. Appl. Manag. Eng. 4 (1) (2021) 194-214

Sugumaran, V., Muralidharan, V., \& Hegde, B.K. (2010). Intelligent process selection for NTM - A neural network approach. International Journal of Industrial Engineering Research and Development, 1(1), 87-96.

Talib, F., \& Asjad, M. (2019). Prioritisation and selection of non-traditional machining processes and their criteria using analytic hierarchy process approach. International Journal of Process Management and Benchmarking, 9(4), 522-546.

Temuçin, T., Tozan, H., Valíček, J., \& Harničárová, M. (2013). A fuzzy based decision support model for non-traditional machining process selection. Tehnicki vjesnik Technical Gazette, 20(5), 787-793.

Xu, W.J., Fang, J.C., \& Lu, Y.S. (2002). Study on ceramic cutting by plasma arc. Journal of Materials Processing Technology, 129(1-3), 152-156.

Yurdakul, M., \& Cçogun, C. (2003). Development of a multi-attribute selection procedure for non-traditional machining processes. Proceedings of the Institution of Mechanical Engineers, Part B: Journal of Engineering Manufacture, 217(7), 993-1009.

Yurdakul, M., \& İç, Y.T. (2019). Comparison of fuzzy and crisp versions of an AHP and TOPSIS model for nontraditional manufacturing process ranking decision. Journal of Advanced Manufacturing Systems, 18(2), 167-192.

Yurdakul, M., İç, Y.T., \& Atalay, K.D. (2019). Development of an intuitionistic fuzzy ranking model for nontraditional machining processes. Soft Computing, 24(1), 1-16.

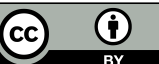

(C) 2018 by the authors. Submitted for possible open access publication under the terms and conditions of the Creative Commons Attribution (CC BY) license (http://creativecommons.org/licenses/by/4.0/). 